\title{
IOT based Smart Waste Management
}

\author{
Prof. Indu Anoop ${ }^{1}$, Ayush Jain ${ }^{1}$, Shweta Pathak ${ }^{1}$, Gauri Yadav ${ }^{1}$ \\ Dept of Information Technology, Vidyalankar Institute of Technology, Mumbai, India ${ }^{1}$
}

\begin{abstract}
Many times, in our city we see that the garbage bins or dustbins placed at public places are overloaded. It creates unhygienic conditions for people as well as ugliness to that place leaving bad smell. To avoid such situations the proposed project will be implemented for efficient waste management using IOT. These dustbins are interfaced with arduino based system having ultrasonic wireless systems along with central system showing current status of garbage, on mobile web application with Android app by Wi-Fi. Hence the status will be updated on to the App. Major part of the proposed project depends upon the working of the Wi-Fi module; essential for its implementation. The main aim of this project is to reduce human resources and efforts along with the enhancement of a smart city vision.
\end{abstract}

Keywords: Ultrasonic Sensor, Djikstra’s Algorithm, IOT, Notify, Android.

\section{INTRODUCTION}

Internet and its applications have become an integral part of today's human lifestyle. It has become an essential tool in every aspect. Due to the tremendous demand and necessity, researchers went beyond connecting just computers into the web. These researches led to the birth of a sensational gizmo, Internet of Things (IOT). Communication over the internet has grown from user user interaction to device - device interactions these days. The IOT concepts were proposed years back, but still it's in the initial stage of commercial deployment.

Home automation industry and transportation industries are seeing rapid growth with IOT. Yet not many articles have been published in this field of study. This document aims in structuring a state of the art review on IOT. The technology, history and applications have been discussed briefly along with various statistics. Since most of the process is done through the internet we must have an active high speed internet connection. The technology can be simply explained as a connection between human computers-things. All the equipment's we use in our day to day life can be controlled and monitored using the IOT. A majority of process is done with the help of sensors in IOT. Sensors are deployed everywhere and these sensors convert raw physical data into digital signals and transmits them to its control centre. By this way we can monitor environment changes remotely from any part of the world via internet. This system's architecture would be based on context of operations and processes in real-time scenarios. Smart collection bin works in the similar manner with the ultrasonic sensor that indicates its depth of garbage in the bin. The ultrasonic sensor will show us the various levels of garbage in the dustbins and to send its output ahead when its threshold level is crossed. These details are further given to the arduino and the controller gives the details to the transmitter module (Wi-Fi module). At the receiver section a mobile handset is needed to be connected to the Wi-Fi router so the details of the garbage bin are displayed onto the Android Application of our mobile handset.

\section{LITERATURE SURVEY}

This is not an original idea, for the implementation of smart garbage bin; the idea has existed for many years, After the IOT field finding its grip in our lives. This is, however an original plan for designing a smart garbage in with ultrasonic sensor and Wi-Fi module for transmission of data.

Top-k Query based dynamic scheduling for IOT enabled small city waste collection by Theodoros Anagnostopoulos, Arkady Zaslavsky, Alexey Medvedev, Sergei Khoruzhnicov. It gave us the concept of dynamic scheduling required for the cleaning of dustbin and the Top-k query led us to priority based cleaning of dustbins.

Smart Garbage Management System by Vikrant Bhor, Pankaj Morajkar, Maheshwar Gurav, Dishant Pandya. It provided us with additional details and designs needed for flow and management of garbage while collection.It provided the details about the hardware required for detecting the level of garbage.

IoT-Based Smart Garbage System for efficient food waste management by Insung Hong, Sunghoi Park, Beomseok Lee, Jaekeun Lee, Daebeom Jeong, Sehyun Park. This paper gave the overview working of the IOT based smart garbage bin and the food management. It includes the information about all the ways to manage the collection of the garbage.

A Review and Evaluations of Shortest Path Algorithms by Kairanbay Magzhan, Hajar Mat Jani: This gave the information about the algorithm to be used.It provides the information about the Djikstra's algorithm and why this algorithm should be preferred over other algorithms to calculate the shortest path.

\section{PROBLEM STATEMENT}

The traditional methods employed by the organizations have the following limitations: 
1. The garbage keeps lying near the bin.

2. It serves as a breeding ground for stray dogs and various animals.

3. The collection mechanism is not efficient and it is a tedious job.

The collection will be done on timely basis, so that the garbage does not keep lying near the bins. It will be an efficient system and will save huge amount of fuel.

\section{PROPOSED SYSTEM}

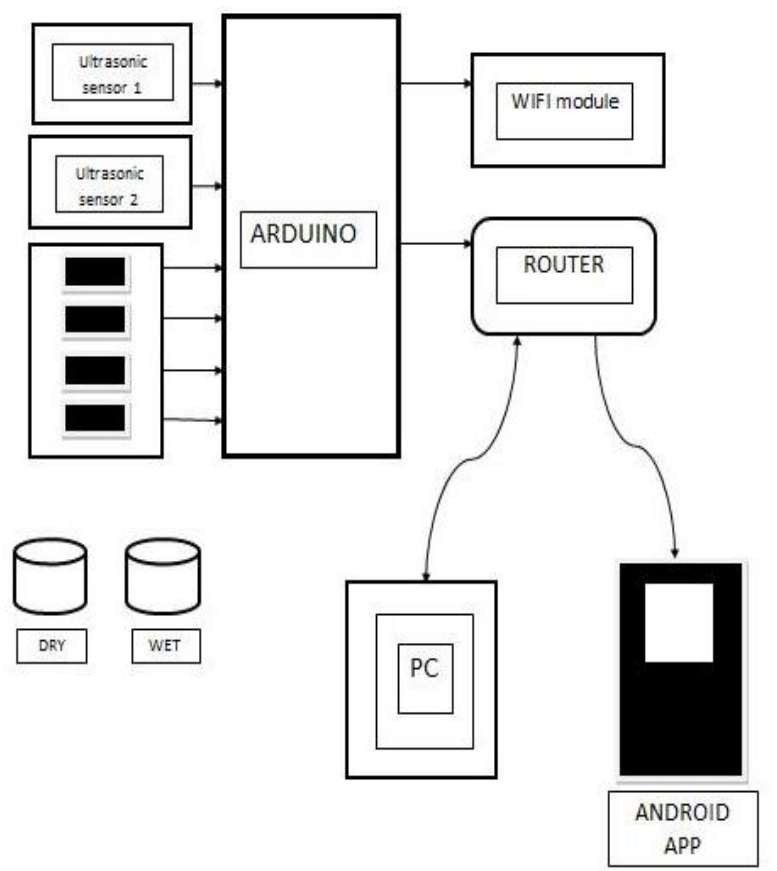

Figure: 1 Proposed System Architecture

1. The arduino will get the level of the garbage from the ultrasonic sensor.

2. The Dip switch will provide the code, using which the location of the dustbin can be identified.

3. The server (Android) will check for the threshold level and if the level is high it will send the notification to collect the garbage.

\section{ADVANTAGES AND DISADVANTAGES}

\section{A) ADVANTAGES:}

1. The garbage will be collected on time-to-time basis.

2. There would not be any bad smell around the bin.

3. Real time notification to collect the garbage.

4. Saving on fuel consumption, thus reducing the threat to the environment.

\section{B) DISADVANTAGES:}

1. It requires a well structured hardware.

2. The onetime cost of installation will be higher than the present technique.

\section{CONCLUSION}

This project work is the implementation of smart garbage management system using ultrasonic sensor, arduino and $\mathrm{Wi}-\mathrm{Fi}$ module. This system assures the cleaning of dustbins soon when the garbage level reaches its maximum. This reduces the total number of trips of garbage collection vehicle and hence reduces the overall expenditure associated with the garbage collection. It ultimately helps to keep cleanliness in the society. Therefore, the smart garbage management system makes the garbage collection more efficient. Smart dustbin helps us to reduce pollution. This project ensures waste collection on time which inturn ensures less contamination of environment, no spread of disease and a cleaner surrounding.

\section{REFERENCES}

[1] Theodoros.Anagnostopoulos1,Arkady.Zaslavsky 2,1, Alexey Medvedev1, Sergei Khoruzhnicov1" Top-k Query based Dynamic Scheduling for IoTenabled Smart City Waste Collection" $201516^{\text {th }}$ IEEE International Conference on Mobile Data Management.

[2] Vikrant Bhor, Pankaj Morajkar, Maheshwar Gurav, Dishant Pandya4 "Smart Garbage Management System" International Journal of Engineering Research \& Technology (IJERT) ISSN: 2278-0181 IJERTV4IS031175 Vol. 4 Issue 03, March-2015.

[3] Insung Hong, Sunghoi Park, Beomseok Lee, Jaekeun Lee, Daebeom Jeong, and Sehyun Park, "IoT-Based Smart Garbage System for Efficient Food Waste Management", The Scientific World Journal Volume 2014 (2014), Article ID 646953.

[4] International Journal Of Scientific and Technology Research Volume 2, Issue 6, June 2013. 